\title{
Studies on data uncertainties of the local model of the German Meteorological Service in the catchment area of the river Ilm
}

\author{
K. Pfannschmidt ${ }^{1,2}$ and H. Döhler ${ }^{2}$ \\ ${ }^{1}$ Thüringer Landesanstalt für Umwelt und Geologie, Prüssingstraße 25, 07745 Jena, Germany \\ ${ }^{2}$ Friedrich Schiller University of Jena, Ernst-Abbe-Platz 2, 07743 Jena, Germany
}

Received: 7 January 2005 - Revised: 1 August 2005 - Accepted: 1 September 2005 - Published: 16 December 2005

\begin{abstract}
To assess the prognostic values concerning precipitation and air temperature in the river catchment area of the Ilm/Thuringia issued by the German Meteorological Service, the differences between the prognostic values and related measured values were statistically evaluated. The investigations covered the period from November 1999 to December 2003. The spatial resolution corresponds to the LM grid cells and the available data. The observed precipitation values were corrected with regard to systematic wind error in dependence of temperature.

The forecast data were investigated comprehensively in order to quantify the statistical reliability. Therefore, the 2nd moment as the case may be the standard deviation of the differences between observed precipitation values and forecasting precipitation values have been calculated. The investigations were subdivided into the complete stretch of time, the hydrological summer and the hydrological winter. Each measured value was analysed with regard to the 12-, 24-, 36and 48-hour forecast made by the DWD.

As a result, empirical analytical functions were developed to describe adequately the statistical quantities for standard deviation of precipitation and temperature for the periods of hydrological summer and hydrological winter in dependence on forecasting time, mean ground level and roughness (fractal dimension) of the LM-grid cell.
\end{abstract}

\section{Introduction}

After the devastating flood disaster of August 2002 in Germany, the Czech Republic, and Austria, many activities in the field of flood protection were launched.

This event showed clearly that early warning systems are the most effective instrument to prevent disasters due to the generation of a valuable gain in time for far-sighted action (URL[1]). New impetus was also given to the pre- ventive flood protection in Thuringia. Strong efforts were made to improve the protection of the population and to avoid flood damages, for example by modernising the flood warning and signalling service (Hack, 2003). In the Free State of Thuringia, the monitoring network on the watercourses comprises 176 gauges, 52 of which having been selected and established as flood gauging and signalling stations (Spanknebel et al., 1999).

The technical developments of the last years implemented in the German Meteorological Service have led to an improvement of the climate forecast data. The numerical weather prediction model (Local Model, LM) enables the model-based short-term discharge prediction (URL[3]). This constitutes the basis for the implementation of a flood warning and information service for a prototypical Thuringian flood gauging and signalling station. The LM forecast data shall form the basis of a model-based operational discharge prediction with the aim to detect looming flash-floods in good time and to be able to inform accordingly.

For this purpose, the gauge of Gräfinau-Angstedt located in the upper reaches of the Ilm river has been selected because of the experiences and practical results already existing for this partial catchment area (TEG) at the chair of Geoinformatics of the Institute for Geography of the Friedrich Schiller University of Jena (Staudenrausch, 2000; Fritzsche, 2001) For hydrological modelling of the TEG of Gräfinau-Angstedt the Precipitation-Runoff Modelling System/Modular Modelling System (PRMS/MMS) (Leavesley and Stannard, 1995) will be used based on the distributive approach of the Hydrological Response Units (HRUs).

The prognostic uncertainty calculated for the hourly precipitation and temperature forecast values will be used as $\sigma$ borders in the operational working of a prognostic discharge model for the TEG of Gräfinau-Angstedt. 


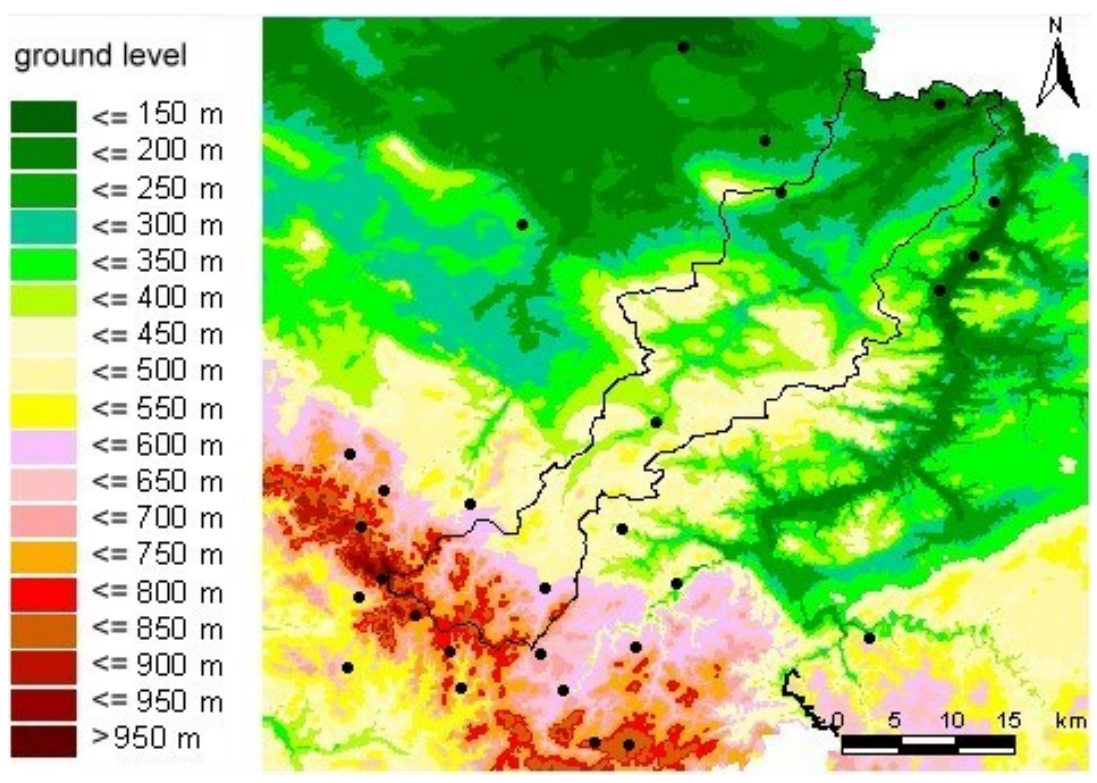

Fig. 1. Ground level and selected stations $(\bullet)$ with catchment boundary of the Ilm (-).

\section{The local model of the German Meteorological Ser- vice (DWD)}

The LM is an operational, hydrodynamical weather forecast model solving a prognostic equation for the vertical movement. A square grid composed of elementary areas of $49 \mathrm{~km}^{2}$ covers the whole area of Central Europe. (URL[2]) The Local Model forecast started in November 1999. The model is able to resolve weather-relevant local landscape details and small-scale meteorological structures. Additionally to the horizontal and vertical wind components, pressure and soil moisture, the LM provides air temperature values and hourly liquid and solid precipitation totals. In this connection 48hour model calculations are carried out that provide current forecast data, refreshed every $12 \mathrm{~h}$. These forecast data shall form the basis of a model-based operative discharge prediction with the aim to detect looming flash-floods and to provide adequate information for early warning systems.

\section{The river catchment area of the Ilm}

As prototypical river catchment area (FEG) the Ilm river catchment in Thuringia, in particular the partial catchment area (TEG) of Gräfinau-Angstedt located in the upper reaches, has been selected.

With a flowing length of about $135 \mathrm{~km}$, the Ilm is a relatively small river draining an area of about $1025 \mathrm{~km}^{2}$.

The difference in altitude between the source and the mouth is $848 \mathrm{~m}$ (see Fig. 1). The mean annual discharge of the $\mathrm{Ilm}$ is $6.59 \mathrm{~m}^{3} / \mathrm{s}$. From the climatic point of view, Thuringia is located within the temperate zone of transition, characterized by the maritime coastal climate with Atlantic influences on the one hand (Thuringian Forest) and continen- tal climatic influences on the other hand (Thuringian Basin) (Bongartz, 2001).

The mean annual temperatures are around $5^{\circ} \mathrm{C}$ in the Thuringian Forest, $7^{\circ} \mathrm{C}$ in the Ilm-Saale-Ohrdruf zone and $8^{\circ} \mathrm{C}$ in the Inner-Thuringian lowland. These differences are caused by the different altitudes and windward/lee effects with the prevailing south-west winds in the low mountain range. With regard to precipitation, the study region has to be subdivided into a low mountain and a summer rain type. In the cool and damp zones of the ridge of the Thuringian Forest, precipitation of up to $1200 \mathrm{~mm} / \mathrm{year}$ is reached, on the lee side of the Thuringian Forest in the direction of the central Thuringian Basin the annual precipitation is below $500 \mathrm{~mm}$ (Fig. 2). The mean annual snow cover depth is around 400$500 \mathrm{~mm}$ in the Thuringian Forest - a region with abundant snowfall and mostly with settled snow conditions - around $100-300 \mathrm{~mm}$ in the mountain foothills and $<100 \mathrm{~mm}$ in the Thuringian Basin - an area with little snowfall (Bongartz, 2001).

\section{Analysed parameters and investigation period}

The prognostic LM data were analysed with regard to their statistical quality for the catchment area of the Ilm river in Thuringia. The main focus was put on precipitation and air temperature as main input parameters for hydrological models. The investigations covered the period from the beginning of the LM forecast in November 1999 to December 2003. For the study area, a representative selection - concerning the spatial distribution - of LM grid cells to be analysed was determined, taking into consideration the measurement stations available. 

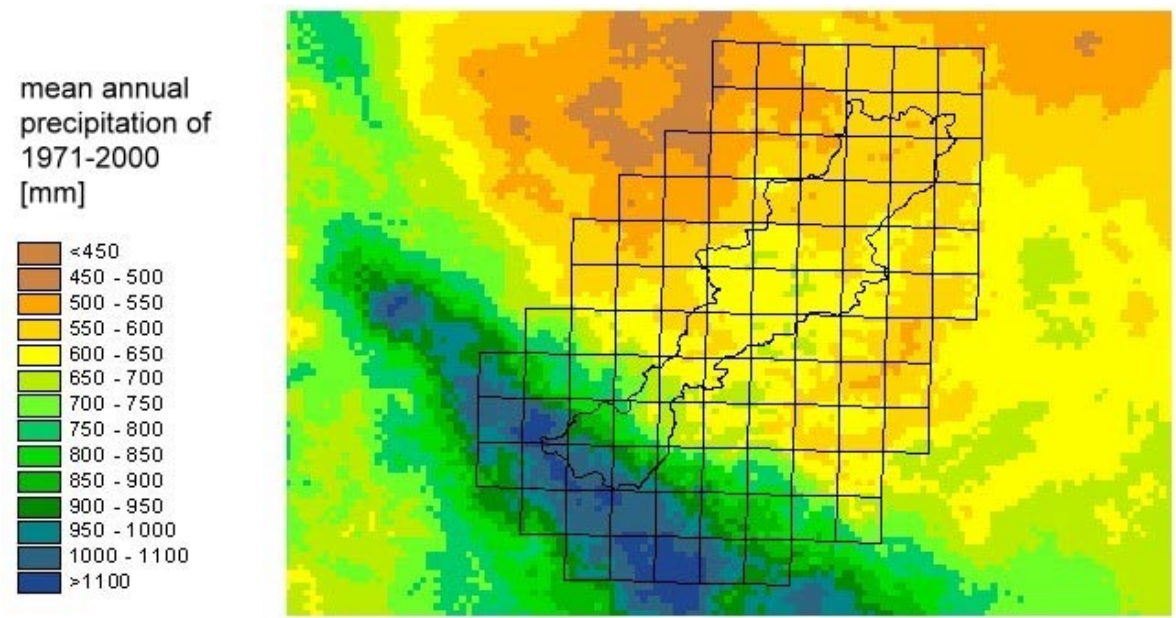

Fig. 2. Mean annual precipitation in the Ilm catchment area with significant LM-grid cells.

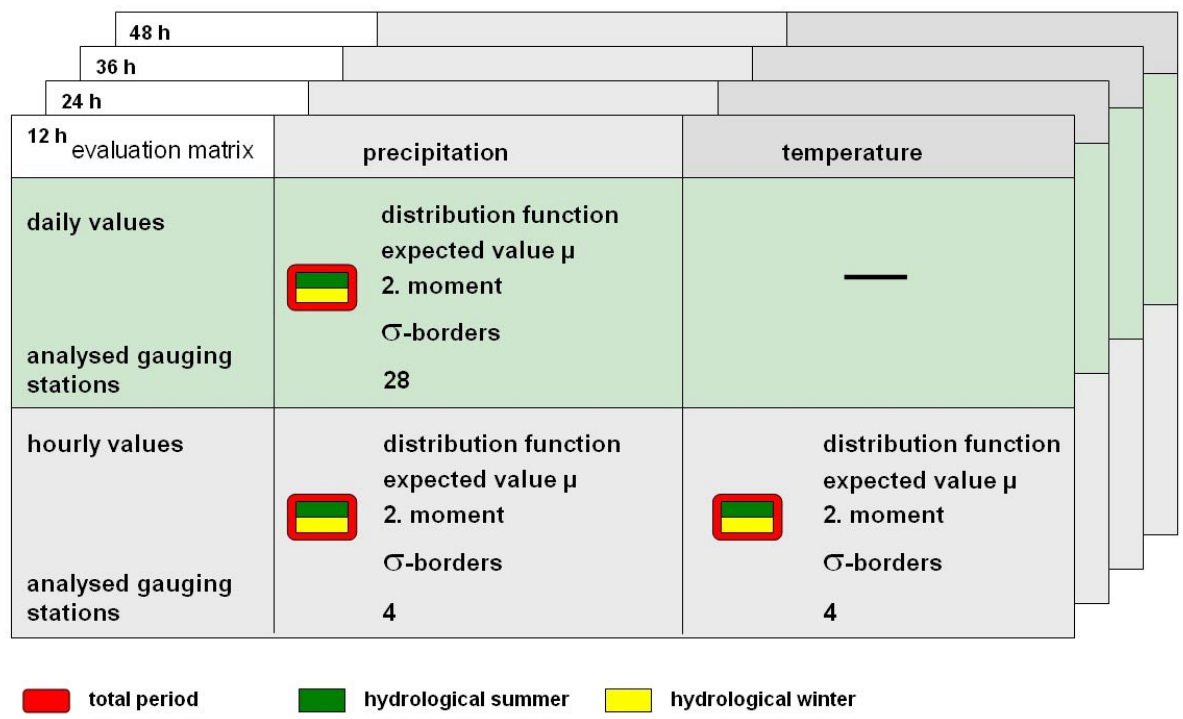

Fig. 3. Schematic overview of the statistical investigations carried out.

\section{Statistical investigations}

The deviations of the forecast data from the measured data were investigated. The forecast was subdivided into four 12-hour periods in accordance with the generation rhythm of the LM forecast. Concerning the seasons, the investigation period was subdivided into the complete stretch of time, the hydrological summer and the hydrological winter. Regarding the aspect of temporal resolution, the measured data available allowed a rating of deviations in daily and hourly sums for precipitations, and in hourly values for temperatures. In addition to the analysis of the distribution functions of differences between observed and forecasting values, the statistical parameters of expected value $\mu$, 2nd moment and $\sigma$-borders were determined (Fig. 3). Altogether, 28 measurement stations were included in the investigation, of which 4 stations (Dornburg, Großobringen, Schmücke,
Oberweißbach) are providing the measured data for precipitation and temperature as hourly values.

To facilitate comparability, the hourly precipitation forecasts for rain and snow available for the period from the beginning of the LM forecast in November 1999 to December 2003, were aggregated to daily sums of precipitation values. In this connection, the CET-based time of reading the measured values of the day and the UTC-based time of the forecast had to be considered. Optimised correction functions were determined to correct the wind error according to Richter (1995). The temperature values required were calculated from the values obtained from the measurement stations according to the method of the arithmetic distance weighted mean. After that, the temperature values were regionalised applying the saturated adiabatic temperature coefficient. 


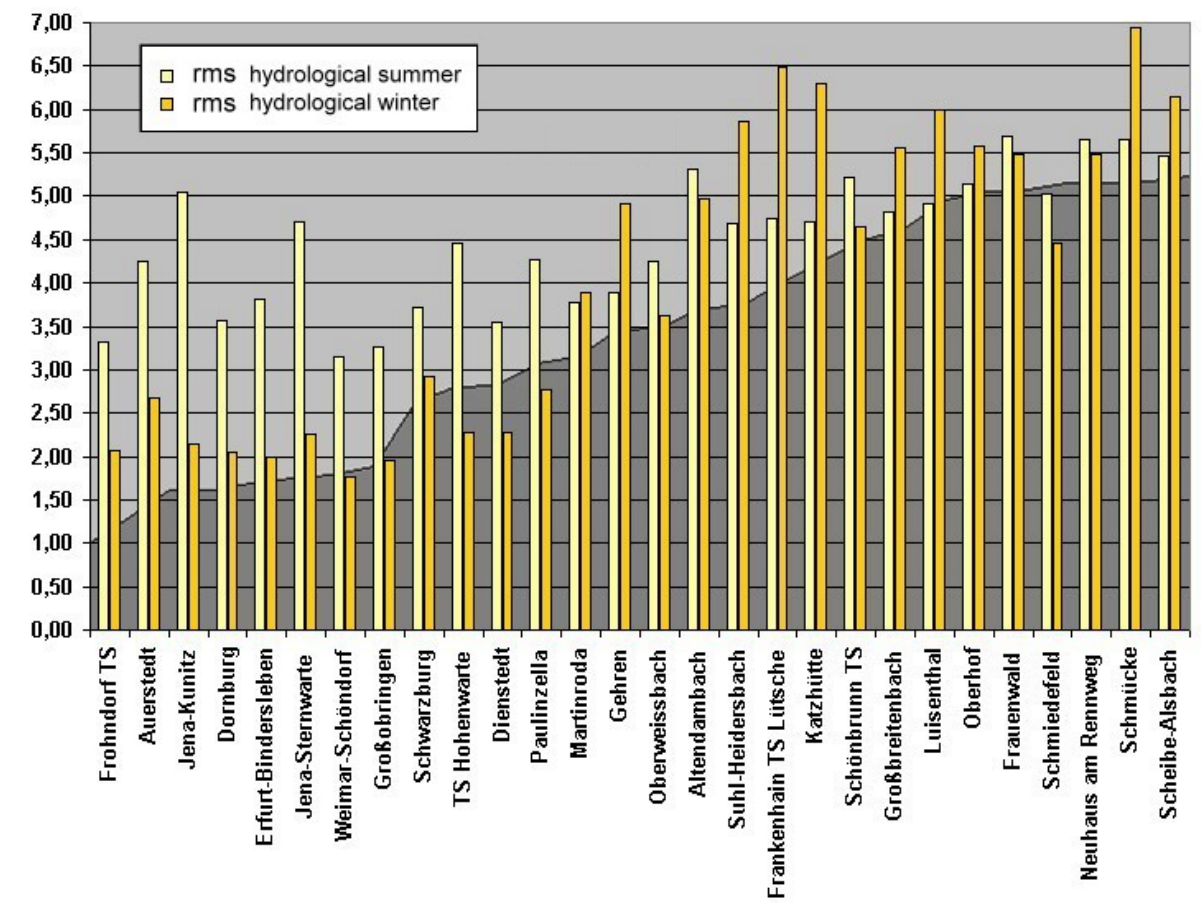

Fig. 4. Root-mean-square deviation of the daily precipitation [mm/day] values with altitude profile of the stations subject to investigation.

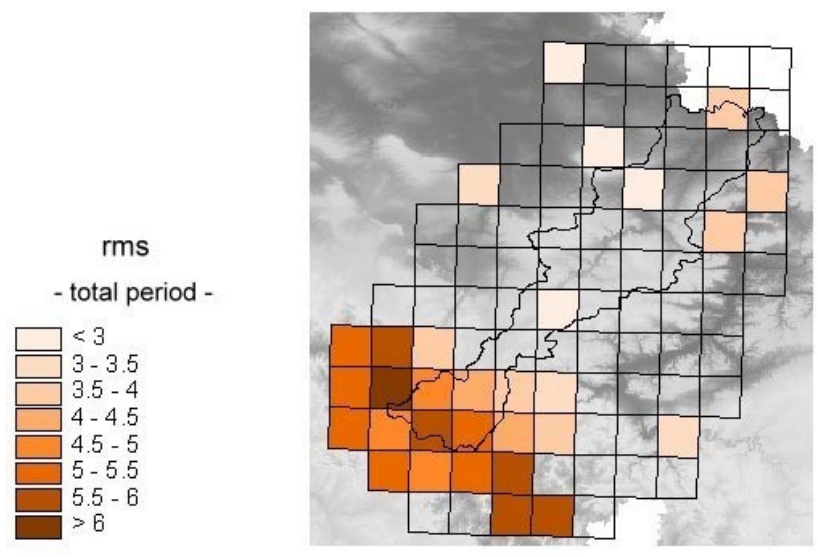

Fig. 5. Spatial distribution of the root-mean-square deviations (rms) of the daily precipitation values in the area subject to investigation.

Applying suitable methods, the corrected hourly and daily precipitation sums were regionalised with regard to the calculated average long-term precipitation mean of the related grid cell for the period from 1970 to 2000. For that purpose the quotient of LM-cell mean and the precipitation mean of the station was evaluated.

Now, the differences between the daily LM sums and the corrected and regionalised readings were analysed. Therefore, empirical distribution functions, the expected value and the 2nd moment $\mathrm{M}_{2}$ were determined.

The 2 nd moment is a quadratic distance measure with regard to the value zero. Using the basic parameter $\mathrm{M}_{2}$ ensures the absolute comparability of the stations with each other.

Figure 4 indicates the root-mean-square deviations $\sigma\left(\sigma=\sqrt{\mathrm{M}_{2}}\right)$ for different stations (hydrological summer and winter are separated). For comparison, the altitude profile of the respective stations is shown in the background.

Figure 5 shows the distribution of the root-mean-square deviations for the complete period in the river catchment area subject to investigation.

The statistical quality calculated this way was assessed with regard to special regional features in view of position and altitude as well as seasonal differences.

Concerning the distribution functions the conclusion was drawn that an optimum adaptation to the analysed distributions was feasible by means of the Lorentz function in Eq. (1) (Fig. 6).

$f(x)=\frac{a}{1+b(x-\mu)^{2}}$

with the expected value $\mu$ and the half-value width .

As the temporal resolution of the prognosticated discharge of the forecast model must be equal to the temporal resolution of the input LM forecast data, it was also necessary to consider the statistical quality of the hourly forecast data.

The hourly precipitation values taken into consideration were regionalised to the respective LM grid, such as the daily sums. The subsequent statistical quality rating proceeded in analogy to the daily sums.

To rate the statistical quality of the temperature forecasts, they were analysed with an hourly resolution. Again, the differences between LM and the measured values were analysed in analogy to the evaluation of precipitation. 


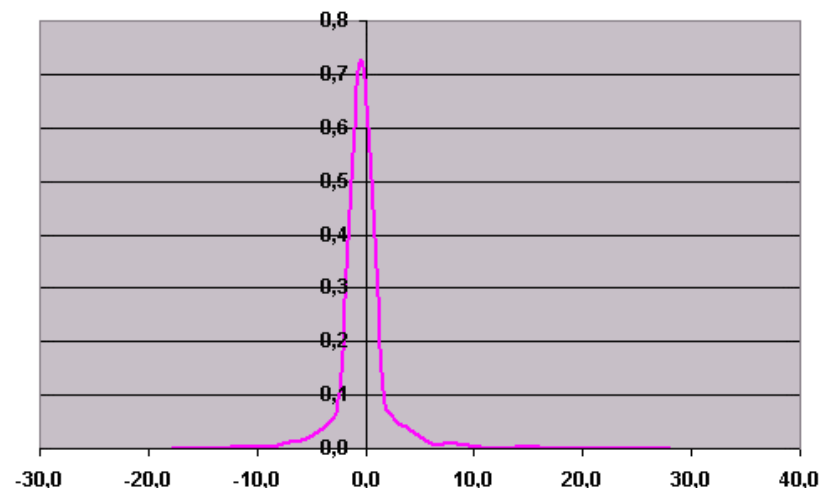

Fig. 6. Analyzed distribution function of station Dornburg for daily values.

Resulting from that, propositions on the quality of the LM forecast data as function of time and location of stations in the hourly and daily time resolutions could be made. The analysed distribution functions of the hourly values show a stronger correlation with the Lorentz function than those of the daily values (Fig. 7).

Each of these investigations was made for the 4 forecast periods of the first $12 \mathrm{~h}$, the second, third, and fourth $12 \mathrm{~h}$.

As there was to be expected a dependence of the forecast quality upon the roughness of the surface relief and the ground level, the fractal dimension $D$ (Eq. 2) was calculated for all significant LM grid cells (Barnsley, 1988):

$D=-\frac{d \ln [N(l)]}{d \ln [l]}$ with the property $M=l^{D}$

with $N(l)$ being calculated according to the box-counting algorithm (Falconer, 1990).

\section{Results}

In the course of evaluating the results, analytical functions were developed to describe sufficiently the statistical quantities in dependence on the forecast period, the ground level and the surface profile.

The formulae given below for the root-mean-square deviation of the dayly values were developed with values being equalised through 30 stations and in case of hourly values through 4 stations.

The basis functions $H_{j}^{n}$ and $r_{j}$ was estimated by non-linear optimisation of the parameters $h_{j}$ and $f d_{j}$ (see below) relative to the calculated $\sigma$-values. The empirical parameters in Eqs. (4-7) result from linear fit to the chosen basis functions. For smart description of the uncertainties $\sigma$ in Eqs. (47) auxiliary variables was introduced. Equation (3) describes the generalised dependence of the altitude related to a mean value.

The following definitions apply:

$j$ - index of the LM grid cell

$t[h]-$ forecasting time $\tau=(t / 12-1)$

$f d_{j}$ - the fractal dimension of the LM grid cell,

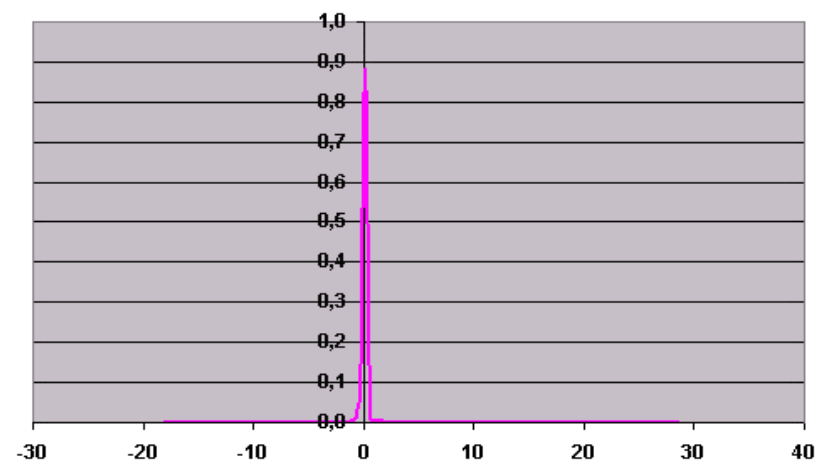

Fig. 7. Analyzed distribution function of station Dornburg for hourly values.

$r_{j}=f d_{j}-2$

$h_{j}$ - the altitude of the LM grid cell

$h_{\text {mittel }}$ - is the mean value of the altitude of all LM grid cells analysed

$n$-empirical exponent

$H_{j}^{n}=\left(\frac{h_{j}}{h_{\text {mittel }}}\right)^{\frac{1}{n}}$

Precipitation - hydrological summer:

$$
\begin{aligned}
\sigma_{S o}(\tau, j) & =0,41 r_{j}+0,429 H_{j}^{3}+ \\
\tau & \left(-0,04 r_{j}+0,061566 H_{j}^{3}\right)
\end{aligned}
$$

Precipitation - hydrological winter:

$$
\begin{aligned}
& \sigma_{W i}(\tau, j)= 0,327 r_{j}+0,3873 H_{j}^{1}+ \\
& \tau\left(0,011 r_{j}+\frac{1}{3}\left(0,518 H_{j}^{1.8}-0,3873 H_{j}^{1}\right)\right)
\end{aligned}
$$

Temperature - hydrological summer:

$$
\begin{aligned}
\sigma_{S o}(\tau, j)= & 0,421 r_{j}+1,8 H_{j}^{-7}+ \\
\tau & \left(0,01 r_{j}+0,1066 H_{j}^{-7}\right)
\end{aligned}
$$

Temperature - hydrological winter:

$$
\begin{aligned}
\sigma_{W i}(\tau, j) & =0,428 r_{j}+1,804 H_{j}^{-7}+ \\
\tau & \left(6.66 \cdot 10^{-4} r_{j}+\frac{1}{3}\left(1,982 H_{j}^{-5}-1,804 H_{j}^{-7}\right)\right)
\end{aligned}
$$

\section{Summary}

In the majority of the analysed stations, the $\sigma$ value of daily precipitation in the hydrological summer exceeds that of the hydrological winter (except for some mountain stations of the Thuringian Forest).

The $\sigma$ values of precipitation in the summer increase only insignificantly with the altitude ( $n=3$, see Eqs. 3 and 4), in 
the winter there is a stronger dependence on the altitude $(n=1$ respectively $n=1.8$ in Eq. 5).

The $\sigma$ values of temperature are inversely proportional to the altitude. Here, the altitude values have only an insignificant influence in summer and winter ( $n=5$ respectively $n=7$, see Eqs. 6 and 7). In all precipitation and temperature values analysed, the influence of the surface roughness is of the same scale. The dependence of forecast time is nearly linear.

The distribution functions of the differences between measured values and forecasting values follow the Lorentz line. This property is even more striking in the hourly values. In general, hourly values reveal greater deviations in summer, increasing with the altitude/precipitation. The influence of microclimatic conditions - such as the prevailing wind direction, local warming, etc. - has not been included in the present studies due to the lack of available data.

It is possible to calculate the uncertainties of precipitation and temperature by LM-forecasting for each grid cell with the developed analytical functions. On this way the total uncertainty of the hydrological prognostic discharge model can evaluate from the uncertainty of the model itself and the calculated uncertainties of the input data.

Edited by: P. Krause, K. Bongartz, and W.-A. Flügel

Reviewed by: anonymous referees

\section{References}

Barnsley, M.: Fractals everywhere, Academic Press, London Inc., 172-182, 1988.

Bongartz, K.: Untersuchung unterschiedlicher Flächendiskretisierungs- und Modellierungskonzepte für die hydrologische Modellierung am Beispiel Thüringer Vorfluter, Dissertation, FSU Jena, 2001.
Falconer, K.: Fractal Geometry, John Wiley \& Sons, Chichester, New York, Brisbane, Toronto, Singapore, 38-42, 1990.

Fritzsche, C.: Vergleichende ereignisbezogene Modellierung der Abflussbildung mit PRMS/MMS und TOPMODEL in zwei kleinen Quelleinzugsgebieten im Thüringer Wald, Diplomarbeit, FSU Jena, 2001.

Hack,H.-P.: Vorbeugender Hochwasserschutz in Thüringen, Thüringer Ministerium für Landwirtschaft, Naturschutz und Umwelt, 2003

Leavesley, G. H. and Stannard, L. G.: The Precipitation-Runoff Modelling System - PRMS, in: Computer Models of Watershed Hydrology, edited by: Singh, V. P., Water Resources Publications, 281-310, 1995.

Richter, D.: Ergebnisse methodischer Untersuchungen zur Korrektur des systematischen Messfehlers des HellmannNiederschlagsmessers, Berichte des Deutschen Wetterdienstes 194, Selbstverlag des DWD, Offenbach am Main, 1995.

Spanknebel, G., Kaufmann, M., Kowalski, B., and Kelm, R.: Modernisierung des Hochwasserwarn- und Meldedienstes im Freistaat Thüringen, Wasserwirtschaft/Wassertechnik, 4, pp. 47, 1999.

Staudenrausch, H.: Untersuchungen zur hydrologischen Topologie von Landschaftsobjekten für die distributive Flussgebietsmodellierung, Dissertation, FSU Jena, 2000.

URL[1]: Deutsches Komitee für Katastrophenvorsorge e.V.: http: //www.dkkv.org/, last access: 09.11.2004.

URL[2]: Deutscher Wetterdienst DWD: Numerische Wettervorhersagemodelle des DWD-Das Lokalmodell LM, http:// www.dwd.de/de/FundE/Analyse/Modellierung/lm.htm, last access: 09.11.2004.

URL[3]: Buchholz, O.: Hochwasservorhersage auf Basis eines Echtzeitbetriebs von NASIM, Hydrotec-Ingenieurgesellschaft für Wasser und Umwelt, http://www2.hydrotec.de/, last access: 09.11.2004. 